\title{
Removable Self-Expanding Metal Stents: A Pilot Study for Treatment of Achalasia of the Esophagus
}

From September 1996 to July 1997, four patients (one man, three women, average age 55.6 years), underwent implantation of self-expanding metal stents for the treatment of esophageal achalasia. Previous open surgical myotomy and multiple balthese patients, and they all had symptoms of dysphagia. Barium swallows and manometric examinations confirmed the diagnosis of stage IV esophageal achalasia. The endoscopic examinations identified a rigid loon dilation procedures had failed in all of

stricture extending over $2-3 \mathrm{~cm}$ of the lower third of the esophagus (the histology excluded carcinoma). A nitinol coil sten with a diameter of $18 \mathrm{~mm}$ and $10 \mathrm{~cm}$ in length was placed without dilation, under mild sedation, crossing the gastroesophageal junction (Figure 1). Stent placement was successful and uncomplicated in all cases. During a follow-up period averaging eight months (range 2-12 months), the patients were able to take a normal diet Repeated upper gastrointestinal radio-

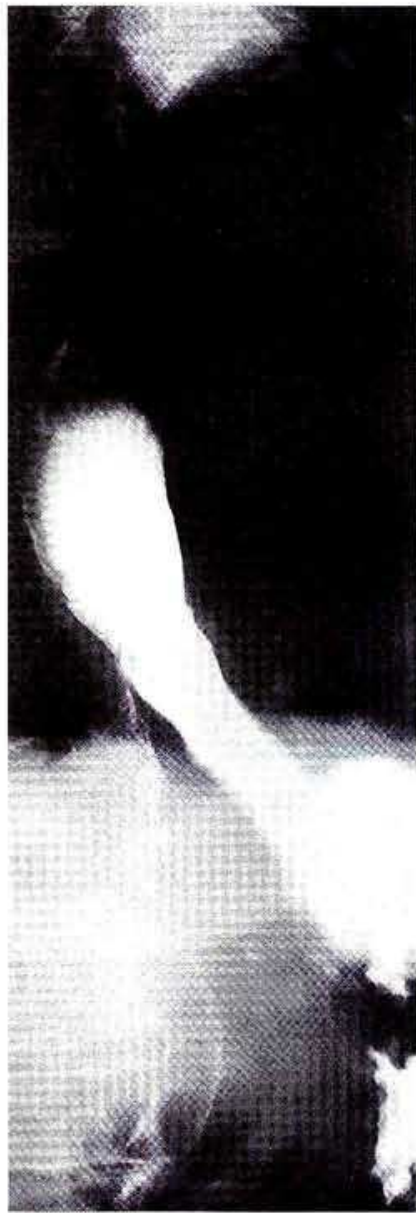

graphs and endoscopic examinations showed no complications such as dislocation, perforation, or hemorrhage. One patient had mild esophagitis, and this was controlled by medical therapy.

At present, the treatment of esophageal achalasia includes drugs that affect muscular tone such as calcium-channel blockers, balloon dilation, open or laparoscopic esophageal myotomy, and more recently endoscopic injection of botulinum toxin into the lower esophageal sphincter Although both surgical and endoscopic treatments are reported to be successful in over $80 \%$ of patients, in the longer term about $3-5 \%$ of patients require a second operation, and about $10-20 \%$ of patients require subsequent dilation treatment (14). Some patients develop a fibrotic stricture in the lower third of the esophagus as a complication of repeated treatment. and this may require surgical resection.

This limited report suggests the role that stents may play in the treatment of esophageal achalasia in selected patients. We believe that self-expanding metal stents may be a new alternative in patients in
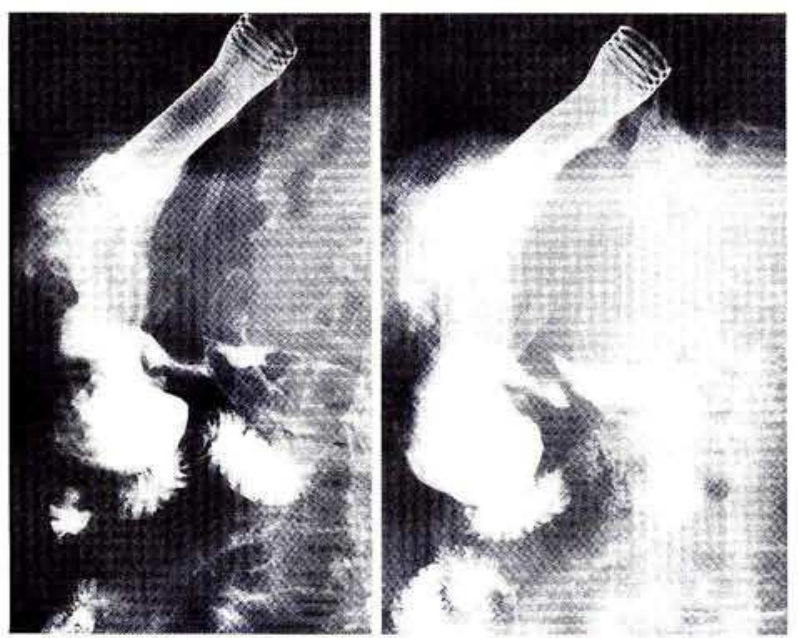
whom standard treatments have failed. The ease of implantation is a major factor favoring the use of metal stents. The use of the coil design allows the stent to be removed in the event of malpositioning, migration, or patient intolerance.

\section{G. D. De Palma, C. Catanzano}

Central Digestive Endoscopy Service, Faculty of Medicine and Surgery, University of Naples, Italy

\section{References}

1. Vantrappen G, Hellemans J. Treatment of achalasia and related motor disorders. Gastroenterology 1980; 79: 144-54.

2. Ferguson MK. Achalasia: current evaluation and therapy. Ann Thorac Surg 1991; 52: 236-42.

3. Pasricha PJ, Ravich WJ, Hendrix TR, et al. Intrasphincteric botulinum toxin for treatment of achalasia. N Engl J Med 1995; 332: 774-8.
4. Swanstrom LL, Penning J. Laparoscopic esophagomyotomy for achalasia. Surg Endosc 1995; 9: 286-92.

Corresponding Author

G. D. De Palma, M.D.

Via De Gasperi 7

80033 Cicciano (Napoli)

Italy

Fax: + 39-81-8248682 